\title{
Granzyme A in Chikungunya and Other Arboviral Infections
}

\section{OPEN ACCESS}

Edited by:

Lisa F. P. Ng

Singapore Immunology Network (A*STAR), Singapore

Reviewed by:

Pierre Roques,

CEA Saclay, France Julian Pardo,

Fundacion Agencia Aragonesa para la Investigacion y el Desarrollo, Spain

*Correspondence:

Alessandra S. Schanoski alessandra.schanoki@butantan.gov.br Andreas Suhrbier Andreas.Suhrbier@ qimrberghofer.edu.au

†These authors share first authorship

¥These authors share last authorship

Specialty section: This article was submitted to Viral Immunology,

a section of the journal

Frontiers in Immunology

Received: 31 July 2019 Accepted: 17 December 2019 Published: 14 January 2020

Citation:

Schanoski AS, Le TT, Kaiserman D, Rowe C, Prow NA, Barboza DD,

Santos CA, Zanotto PMA, Magalhães KG, Aurelio L, Muller D,

Young $P$, Zhao $P$, Bird PI and Suhrbier A (2020) Granzyme A in Chikungunya and Other Arboviral Infections. Front. Immunol. 10:3083. doi: 10.3389/fimmu.2019.03083

\begin{abstract}
Alessandra S. Schanoski ${ }^{1 *}$, Thuy T. Le ${ }^{2+}$, Dion Kaiserman ${ }^{3}$, Caitlin Rowe ${ }^{3}$, Natalie A. Prow ${ }^{2,4}$, Diego D. Barboza ${ }^{1}$, Cliomar A. Santos ${ }^{5}$, Paolo M. A. Zanotto ${ }^{6}$, Kelly G. Magalhães ${ }^{7}$, Luigi Aurelio ${ }^{8}$, David Muller ${ }^{9}$, Paul Young $^{9}$, Peishen Zhao ${ }^{8}$, Phillip I. Bird ${ }^{3 \neq}$ and Andreas Suhrbier ${ }^{2,4 * \neq}$
\end{abstract}

${ }^{1}$ Bacteriology Laboratory, Butantan Institute, São Paulo, Brazil, ${ }^{2}$ QIMR Berghofer Medical Research Institute, Brisbane, QLD, Australia, ${ }^{3}$ Department of Biochemistry and Molecular Biology, Biomedicine Discovery Institute, Monash University, Melbourne, VIC, Australia, ${ }^{4}$ Australian Infectious Disease Research Centre, University of Queensland, Brisbane, QLD, Australia, ${ }^{5}$ Health Foundation Parreiras Horta, Central Laboratory of Public Health, State Secretary for Health, Aracajú, Brazil, ${ }^{6}$ Laboratory of Molecular Evolution and Bioinformatics, Department of Microbiology, Biomedical Sciences Institute, University of São Paulo, São Paulo, Brazil, ${ }^{7}$ Laboratory of Immunology and Inflammation, University of Brasilia, Brasilia, Brazil, ${ }^{8}$ Drug Discovery Biology and Department of Pharmacology, Monash Institute of Pharmaceutical Sciences, Monash University, Parkville, VIC, Australia, ${ }^{9}$ School of Chemistry and Molecular Biosciences, University of Queensland, Brisbane, QLD, Australia

Granzyme A (GzmA) is secreted by cytotoxic lymphocytes and has traditionally been viewed as a mediator of cell death. However, a growing body of data suggests the physiological role of GzmA is promotion of inflammation. Here, we show that GzmA is significantly elevated in the sera of chikungunya virus (CHIKV) patients and that GzmA levels correlated with viral loads and disease scores in these patients. Serum GzmA levels were also elevated in CHIKV mouse models, with NK cells the likely source. Infection of mice deficient in type I interferon responses with CHIKV, Zika virus, or dengue virus resulted in high levels of circulating GzmA. We also show that subcutaneous injection of enzymically active recombinant mouse GzmA was able to mediate inflammation, both locally at the injection site as well as at a distant site. Protease activated receptors (PARs) may represent targets for GzmA, and we show that treatment with PAR antagonist ameliorated GzmA- and CHIKV-mediated inflammation.

Keywords: chikungunya, granzyme A, NK cell, arthritis, arbovirus

\section{INTRODUCTION}

Granzyme A (GzmA) is a granule trypsin-like serine protease (trypase) secreted by various cytotoxic lymphocytes including NK cells $(1,2)$, NKT cells (3), CD8 cytotoxic T lymphocytes (CTL) (4), and CD4 CTL (5-7). The established view is that GzmA enters target cells through perforin pores at the immunological synapse (contact site between the cytotoxic lymphocyte and the target cell) to mediate caspase-independent cell death via cleavage of members of the SET complex $(1,8)$. Although GzmA often remains classified as a cytotoxic mediator $(7,9,10)$, an emerging paradigm is that the primary physiological role of GzmA is promotion of inflammation in a variety of settings (11-15). GzmA has, for instance, been implicated as an important proinflammatory mediator in inter alia rheumatoid arthritis $(16,17)$, psoriasis (18), and osteoarthritis (19). A number of mechanisms have been proposed whereby GzmA might mediate this activity, including intracellular cleavage of pro-IL-1 $\beta$ (20) or SET complex proteins $(21,22)$, and/or extracellular cleavage of pro-urokinase (23) or protease activated receptors 1 and 2 (PAR-1 and PAR-2) (24-27) or potentiation of TLR2/4 (28) and/or 
TLR9 (29) signaling, with the latter two potentially not requiring GzmA's protease activity. GzmA is also reported to be a critical effector molecule for human Treg function (30). Serpinb6b is a specific inhibitor of mouse GzmA that forms a covalent stoichiometric 1:1 inhibitory complex with GzmA (31). Serpinb6b is upregulated in resolution phase (anti-inflammatory) macrophages in mice (32), perhaps providing further support for the pro-inflammatory role of GzmA. No human equivalent of this serpin has as yet been identified.

Elevated levels of circulating GzmA protein have been observed in a diverse variety of infectious disease settings including viral, bacterial, and parasitic infections (12,33-37). We recently also showed elevated levels of circulating GzmA in nonhuman primates infected with chikungunya virus (CHIKV) (38). Circulating mouse GzmA (mGzmA) does not appear to have, or to induce, significant anti-viral activity against CHIKV (38), although anti-viral activity for $\mathrm{mGzmA}$ (ostensibly independent of cytolytic activity) has been reported for ectromelia (39). CD8 T cells appear to play only a minor role in CHIKV anti-viral activity and disease $(40,41)$. In contrast, Th1 CD4 T cells (42) play a major pathogenic role $(43-45)$, with CD56+ $(46,47)$ NK cells $(42,48,49)$ and perhaps NKT cells $(50)$ also contributing (51).

Herein we report that circulating GzmA is significantly elevated in humans and mice following infection with CHIKV, and show that it is also evaluated in mouse models of Zika virus (ZIKV) and dengue virus (DENV) infections. During CHIKV infection in mice, NK cells appear to be the primary source of $\mathrm{mGzmA}$. Injection of recombinant $\mathrm{mGzmA}$ was also able to induce edema and neutrophil infiltration in mice. Although the molecular mechanisms that underpin GzmA's pro-inflammatory activities in vivo are currently unclear, PAR-1 and PAR-2 may be involved as treatment with PAR-1 and PAR-2 antagonists ameliorated foot swelling induced by recombinant mGzmA. The PAR-1 antagonist, Vorapaxor, was also able to reduce foot swelling after CHIKV infection.

\section{MATERIALS AND METHODS}

\section{Human Sera Collection, Diagnosis, and Patient Information}

Human serum samples were collected in the Brazilian states of Sergipe, São Paulo, and Brasília $(52,53)$. Clinical and sociodemographic data was collected through a questionnaire that participants were asked to complete. Patient samples were collected from consented participants reporting arbovirus-like symptoms in the period between 1 and 3 days post the onset of symptoms. qRT PCR tests were undertaken to test for CHIKV, ZIKV, and DENV RNA as described (52). All CHIKV positive patients tested negative for DENV and ZIKV and all the control patients tested negative for CHIKV, ZIKV and DENV.

\section{Determination of GzmA Levels in Human and Mouse Serum Samples}

Human serum samples were tested for human GzmA (hGzmA) levels using the Human Granzyme A Flex Set (BD Cytometric Bead Array, BD Biosciences, San Diego, CA, USA) and
Fluorescence-Activated Cell Sorting (FACS) using the Canto II Cell Analyzer (BD Biosciences, San Diego, CA, USA) according to manufacturer's protocols. The data were analyzed with the FCAP Array v 3.0.1 software (BD Biosciences, San Diego, CA, USA).

mGzmA levels were determined using an ELISA kit (MyBioSource, San Diego, CA, USA, MBS704766) according to manufacturer's instructions.

\section{Mouse Models of CHIKV, ZIKV, and DENV}

For the adult wild-type mouse model of CHIKV C57BL/ 6 female mice 6-8 weeks old were injected with $10^{4} \mathrm{CCID}_{50} \mathrm{CHIKV}$ (isolate LR2006 OPY1) s.c. into the feet as described $(38,54)$. The mouse model of CHIKV-induced hemorrhagic shock using IRF3 $/ 7^{-/-}$mice has been described previously (55) and involved inoculation with CHIKV as above. The $\mathrm{ZIKV}_{\text {Natal }}$ strain was used to infect 8-12 week old female IFNAR $1^{-/-}$mice s.c. (base of tail) with $10^{4} \mathrm{CCID}_{50}$ as described $(56,57)$. The $\mathrm{ZIKV}_{\text {MR766 }}$ strain was similarly used to infect female IRF3/7 $/ 7^{-}$mice with $10^{3}$ $\mathrm{CCID}_{50}$. The DENV mouse model used 6-8 week old female AG129 mice infected with $10^{5}$ pfu DENV-2 (strain D220) i.p. (58). All mice were euthanized using $\mathrm{CO}_{2}$ when they reached ethically defined disease severity scores. All work with infectious CHIKV was conducted in the biosafety level-3 (PC3) facility at the QIMR Berghofer Medical Research Institute. All work was approved by the QIMRB Institutional Biosafety Committee.

\section{Cell Harvesting and FACS Analyses}

Feet were removed at the indicated times, kept at $4^{\circ} \mathrm{C}$ and tissue was scraped from the bone using a scalpel into RPMI 1640 supplemented with $10 \%$ fetal calf serum (R10) at $4^{\circ} \mathrm{C}(6-8$ feet in $5 \mathrm{mls})$. The tissue suspensions were digested with collagenase/dispase (Roche, Basel, Switzerland, Cat \#10269638001) (1 mg/ml) and DNase I (Roche, Cat\#10104159001) $(0.2 \mathrm{mg} / \mathrm{ml})$ for $30-45 \mathrm{~min}$ at $37^{\circ} \mathrm{C}$ with occasional mixing. Debris was removed by centrifugation at $10 \mathrm{~g}$ for $1 \mathrm{~min}$ at $4^{\circ} \mathrm{C}$, and the supernatant collected and placed into a new $10 \mathrm{ml}$ tube and underlayed with $\approx 5 \mathrm{ml}$ Percoll (GE Healthcare, Sweden) and centrifuged at $600 \mathrm{~g}$ for $30 \mathrm{~min}$ at $4^{\circ} \mathrm{C}$. Cells at the Percoll/medium interface were collected and washed once with R10. Red blood cells were lysed with ACK buffer, and the cells were washed twice with $\mathrm{R} 10$ at $4^{\circ} \mathrm{C}$. Cells were blocked with Fc block (2.4G2 tissue culture supernatant, $\approx 10 \mu \mathrm{g} / \mathrm{ml}$ ) for $20 \mathrm{~min} 4{ }^{\circ} \mathrm{C}$, washed once in phenol red free RPMI supplemented with $2 \%$ fetal calf serum (R2) and were then stained with Live/Dead Aqua (Invitrogen, Carlsbad, California, USA, Cat\#34957) for $15 \mathrm{~min}$ and washed once in R2. Cells were surface stained with anti-NK1.1-BV421 (Biolegend, San Diego, California, USA, clone PK136); anti-CD3-APC (Biolegend, clone 145-2C11); anti-CD4-FITC (Biolegend, clone RM4-5) for $45 \mathrm{~min}$ at $4^{\circ} \mathrm{C}$. Cells were washed twice in $\mathrm{R} 2$ were then fixed and permeabilized with BD Cytofix/Cytoperm for $20 \mathrm{~min}$ and washed twice with $1 \mathrm{x}$ BD Perm/Wash buffer. Cells were then stained with anti-mouse-GzA-PE (Biolegend, clone 3.8G5) in Perm/Wash buffer for $30 \mathrm{~min}$ and then washed twice in Perm/Wash buffer. Cells were than analyzed by FACs using BD LSR Fortessa 4 on the same day. Data was analyzed using BD 
FACSDiva software v8.0.1. Splenocytes were stained as above with the procedure starting with red blood cell lysis.

\section{BLT Assay}

The benzyloxycarbonyl-L-lysine thiobenzyl ester (BLT) assay was undertaken as described (4) but modified by addition of $2 \mathrm{mM}$ EDTA (to inhibit cysteine proteases) and 1\% Igepal (SigmaAldrich, St Louis, MO, USA) (instead of NP40 to lyse the cells). The assay was run in duplicate using $2 \times 10^{5} \mathrm{NK} 1.1+$ and CD3cells per well, with cells FACS-sorted from splenocytes of naive C57BL/6J mice. Positive controls were lysates of two human cell lines, CEM T lymphoblast cells (ATCC CRL-2265) and NK92 NK cell line (ATCC CRL-2407), both known to express hGzmA (1).

\section{Recombinant Mouse GzmA and Serpinb6b}

Recombinant mouse GzmA zymogen was produced in Pichia pastoris and activated as described previously $(59,60)$. Production of recombinant Serpinb6b, and GzmA Serpinb6b binding assays were undertaken as described previously (31). mGzmA was injected s.c. into feet of C57BL/6J mice at the indicated dose and foot swelling measured in the injected foot and the contralateral uninjected foot using digital calipers as described (54). Foot swelling was determined as the percentage increased in height $\mathrm{x}$ width of the metatarsal area relative to the same foot before injection.

\section{Drug Treatments}

Vorapaxar (SCH 530348) was obtained from Axon Medchem (Groningen, Netherlands) and I-343 was synthesized and purified by Dr. Luigi Aurelio (61). Both drugs were dissolved in dimethylformamide (DMF) $(10 \mathrm{mg} / \mathrm{ml})$ and then PBS $(0.5 \% \mathrm{v} / \mathrm{v})$ prior to administration at the indicated dose.

\section{Statistics}

Statistical analysis of experimental data was performed using IBM SPSS Statistics for Windows, Version 19.0. The Spearman correlation was used for hGzmA and CHIKV RNA and disease scores. Two-sample comparison using $t$-test was performed when the difference in variances was $<4$, skewness was $>-2$, and kurtosis was $<2$. Non-parametric data with difference in variances of $<4$ was analyzed using Mann-Whitney $U$-test, if difference of variances was $>4$ the Kolmogorov-Smirnov test was employed. The log rank (Mantel-Cox) test was used for statistical analysis of surviving proportions. The repeat measures ANOVA was used for mGzmA-induced foot swelling.

\section{RESULTS}

\section{Circulating GzmA Levels in CHIKV Patients}

Levels of human GzmA (hGzmA) were measured in a cohort of Brazilian patients, who were confirmed to be CHIKV positive by qRT PCR as described (52). The levels were compared to a cohort of healthy CHIKV negative patients. All serum samples from CHIKV patients were obtained between days 1 and 3 post onset of symptoms as reported by the patient. The mean age was $38 \pm$ 17.1 years for CHIKV patients and $43.5 \pm 15$ years for controls. Of the CHIKV patients, 35 provided their gender as female and
19 provided their gender as male. Of the control patients, 18 provided their gender as female and 5 provided their gender as male. hGzmA levels did not correlate significantly with age (Spearman correlation, $p=0.33$ ), nor were differences between males and females significant ( $p=0.75, t$-test).

hGzmA levels were significantly higher in the CHIKV positive group compared to the control group (Figure 1A), confirming the data obtained from CHIKV infected non-human primates (NHP) and a small cohort of Australian travelers (38). The NHP studies illustrated that serum GzmA levels were quite variable even before infection, and increases were transient, peaking between day 2 and 9 post infection (38). Baseline levels were not available for the human cohort and only a single sample postinfection was available for each patient. Differences from baseline could thus not be determined, nor could we match sampling times with peak hGzmA levels. Nevertheless, serum CHIKV RNA levels correlated significantly and positively with hGzmA levels (Figure 1B). (CT values from CHIKV qRT PCR were available for a number of patients, with relative CHIKV RNA levels nominally taken as the reciprocal of the CT values). A similar correlation was apparent from NHP studies (38). Importantly, hGzmA levels also correlated positively with disease scores (Figure 1C), a key parameter that was not available from NHP studies. Although control subjects in the cohort were overtly healthy at the time that blood was taken, one control patient (hGzmA level $6.76 \mathrm{pg} / \mathrm{ml}$ ) reported a past infection with DENV and was taking a thyroid hormone supplement (62). Clinical histories were not provided by many patients and controls.

\section{Serum GzmA Levels in CHIKV-Infected Wild-Type Mice}

The levels of mouse GzmA (mGzmA) in serum were determined in an adult wild-type mouse model of CHIKV infection (54). This mouse model has been shown to recapitulate many aspects of human infection, inflammatory responses and disease (38, 54, 63). Two peaks in serum $\mathrm{mGzmA}$ levels were apparent on day $2(\approx 200 \mathrm{pg} / \mathrm{ml})$ and day $6(\approx 75 \mathrm{pg} / \mathrm{ml})$ (Figure $2 \mathrm{~A})$, which coincide with peak viremia and peak arthritis $(38,54)$. These two peaks also coincide with the two peaks in foot swelling seen in this model (54) (i) the smaller peak in foot swelling on day 2-3, which is edematous and may be associated with NK cell activity $(42,48)$ and (ii) the larger peak on day 6-7, which is associated with a pronounced mononuclear cellular infiltrate comprising primarily monocytes/macrophages, NK cells and T cells (54).

\section{FACS Analyses of mGzmA Expressing Cells After CHIKV Infection}

To ascertain which cells produce mGzmA during CHIKV infection in the adult wild-type C57BL/6J mouse model, FACS analyses were undertaken using intracellular staining for mGzmA (2). In resting splenocytes about $80 \%$ of NK1.1+, CD3 - cells (NK cells) expressed mGzmA protein in our assays (Supplementary Figure 1A), consistent with previous findings (2). The specificity of the intracellular mGzmA staining was demonstrated by $<0.1 \%$ of cells from $\mathrm{GzmA}^{-/-}$mice staining with anti-mGzmA antibody (Supplementary Figure 1C). 

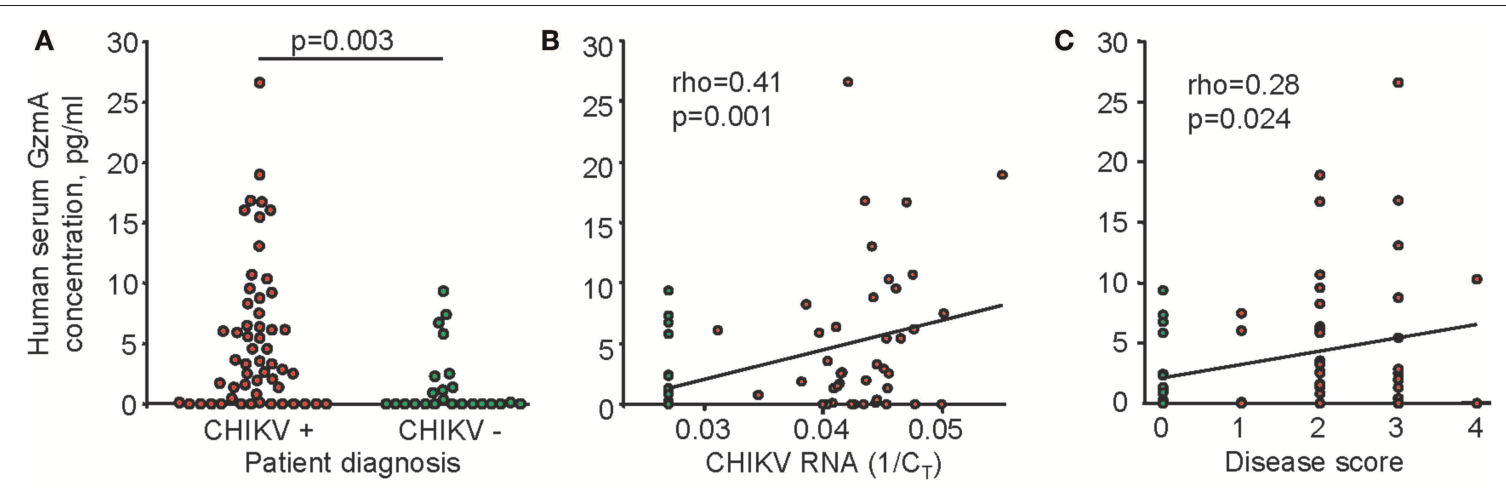

FIGURE 1 | Serum levels of hGzmA in CHIKV and control patients. (A) hGzmA concentrations were determined in sera from $56 \mathrm{CHIKV}$ patients (positive by CHIKV qRT PCR and/or serology, red dots) and 24 healthy controls (negative by CHIKV qRT PCR and/or serology, green dots). Statistics by Kolmogorov-Smirnov test. (B) Spearman correlation between GzmA concentration and $\mathrm{CHIKV}$ RNA levels as determined by qRT PCR. The reciprocal of the $\mathrm{C}_{\mathrm{T}}$ value (1/C $\mathrm{C}_{\mathrm{T}}$ ) was taken as a measure of CHIKV RNA levels, with a $\mathrm{C}_{\mathrm{T}}$ value of 37 deemed to be negative $(1 / 37=0.027$, green dots, $n=24)$. (C) Spearman correlation between hGzmA concentration and disease score. Each of the main symptoms (fever, joint pain, rash, and myalgia) were determined to be present (yes $=1$ or no $=0$ ), and the sum of scores (minimum 0 , maximum 4) provided the disease score. All healthy controls scored 0 (green dots, $n=24$ ).

On day 2 post CHIKV infection the cells infiltrating into the feet (54) comprised $\approx 20 \%$ NK cells (Figure 2, NK1.1+, CD3-), with $\approx 18 \%$ of these expressing detectable $\mathrm{mGzmA}$ (Figure $2 \mathrm{~B}$ ). The proportion of NKT cells (NK1.1+, CD3+), CD4+ CD3+ cells (CD4 T cells) and CD4- CD3 + cells (primarily CD8 T cells) were low $(<5.1 \%)$, with $\mathrm{mGzmA}$ expression seen in $10.6 \%$ of NKT cells and $5.9 \%$ of CD4-CD3+ cells (Figure 2B). On day 6 post CHIKV infection the proportion of NK cells had dropped to $9 \%$, with $51 \%$ of these cells expressing detectable mGzmA (Figure 2C). The proportion of CD4 $+\mathrm{CD} 3+$ cells increased by $\approx 5$ fold and the proportion of CD4-CD3 + cells doubled, but the percentage of these cell expressing $\mathrm{mGzmA}$ did not change (Figure 2C). FACS controls using $\mathrm{GzmA}^{-/-}$mice are shown in Supplementary Figure 2.

Thus, on both day 2 and 6 post CHIKV infection, the major source of circulating mGzmA would appear to be NK cells, with NK cells involved in arthritic immunopathology (and perhaps anti-viral activity) $(42,48,50,64)$. As $80 \%$ of NK cells in the spleen are $\mathrm{mGzmA}+$, one might speculate that the reduction in the percentage of $\mathrm{mGzmA}+\mathrm{NK}$ cells in feet on day 2 $(20.4 \%$ with $18.3 \% \mathrm{mGzmA}+)$ and on day 6 (9\% with $51 \%$ $\mathrm{mGzmA}+$ ) indicates NK cell degranulation, as these figures would be consistent with the high levels of circulating $\mathrm{mGzmA}$ on day 2 and the lower peak on day 6 (Figure 2A). However, these FACS results (Figures $\mathbf{2 B}, \mathbf{C}$ ) could conceivably also arise from preferential recruitment of $\mathrm{mGzmA-negative} \mathrm{NK}$ cells into feet. FACS analyses of splenocytes suggest migration of NK cells out of the spleen by day 2 post infection (as the proportion of NK cells drops from 2 to $1.1 \%$ ) and subsequent expansion of NK cells (65) by day 6 (with the proportion increasing to $5.4 \%$ ) (Supplementary Figure 1B).

Although the CD4 T cells recruited into the arthritic lesions are predominantly $\mathrm{Th} 1$ biased and CD $4 \mathrm{~T}$ cells are major drivers of arthropathy $(40,43,45,51)$, they do not appear to be a major source of mGzmA. CD4-CD3+ cells, primarily CD8 T cells, would be expected to express mGzmA (4); however, CD8 T cells appear to neither have significant protective activities nor immunopathological roles in alphaviral arthritides $(40,66)$. NKT cells might be expected to express GzmA (67) and they may play a role in CHIKV infections, although their relative importance remains to be established (68).

\section{The BLT Assay and Recombinant Murine GzmA}

GzmA is ordinarily stored in granules as a mature protease, with the low $\mathrm{pH}$ of the granule preventing (premature) proteolytic activity (69). hGzmA's activity can be determined via the protease's esterase activity using the benzyloxycarbonyl-L-lysine thiobenzyl ester (BLT) assay (4). NK cells were FACS sorted from the splenocytes of C57BL/6J mice (NK1.1+, CD3-, >98\% pure) and detergent lysates $(\mathrm{pH}=8.1)$ subjected to analysis using the BLT assay. NK cells from C57BL/6J mice, but not NK cells from $\mathrm{GzmA}^{-/-}$mice, showed significant BLT activity (Figure 3A). This confirms that resting splenic NK cells from C57BL/6J mice contain enzymatically active mGzmA (2) and illustrates the utility of the BLT assay for measuring mGzmA activity.

Recombinant $\mathrm{mGzmA}$ and recombinant mouse Serpinb6b were generated as described previously $(31,70)$. Purity and activities are illustrated by Coomassie staining (Figure 3B). When recombinant $\mathrm{mGzmA}$ was incubated with excess SerpinB6b, all the mGzmA was found in the complex (Figure 3B, Excess Serpinb6b), illustrating that the majority of $\mathrm{mGzmA}$ was correctly folded and able to bind the inhibitor. When recombinant Serpinb6b was incubated with excess $\mathrm{mGzmA}$, $>95 \%$ was found in the complex or was cleaved in the reactive center loop (Cleaved Serpinb6b) (Figure 3B, Excess mGzmA), illustrating that most of the recombinant Serpinb6b was correctly folded and able to bind $\mathrm{mGzmA}$. The recombinant $\mathrm{mGzmA}$ was also shown to be active in the BLT assay with heat inactivation destroying the BLT activity (Figure 3C), indicating that the recombinant $\mathrm{mGzmA}$ was enzymically active. 
A

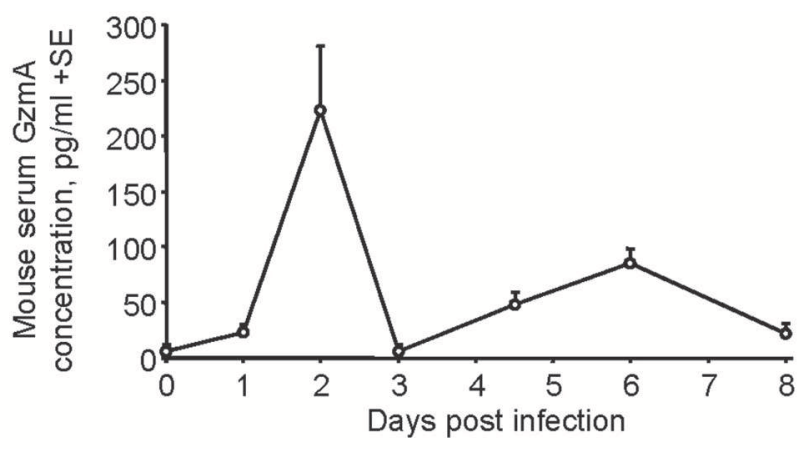

B
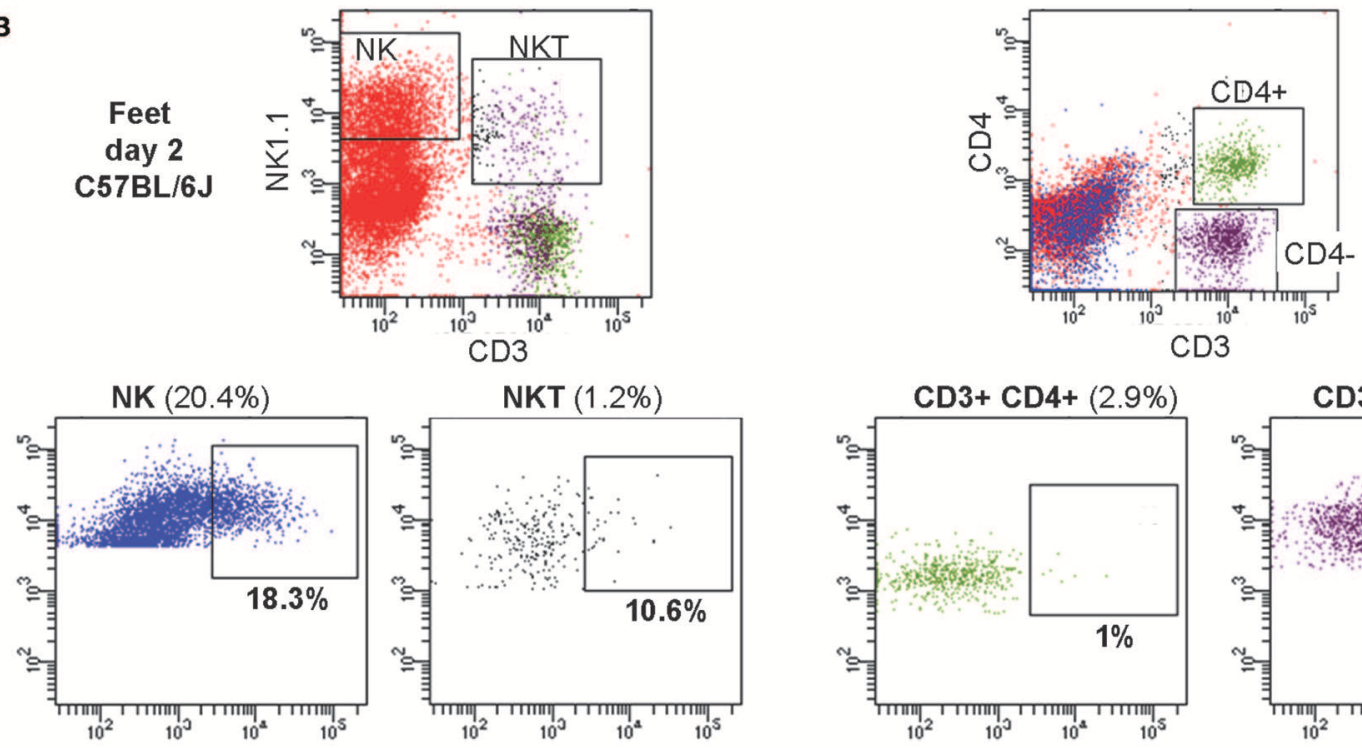

NKT (1.2\%)
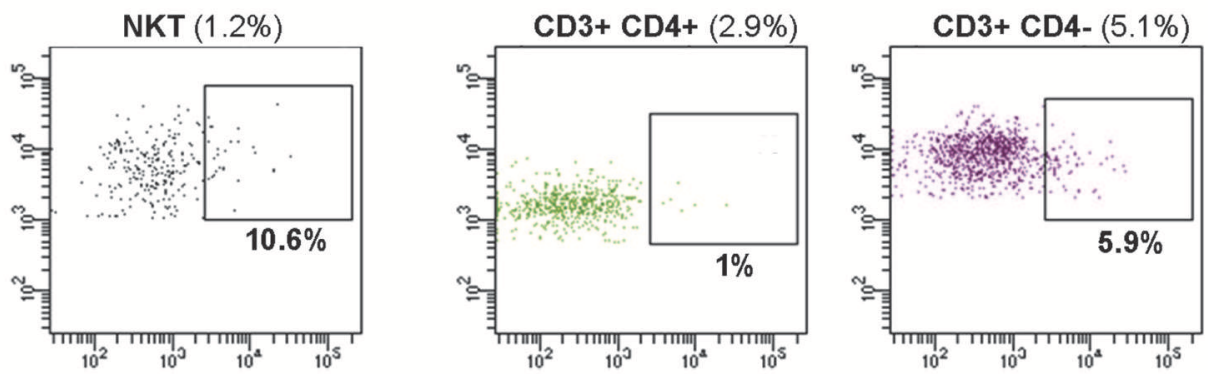

C
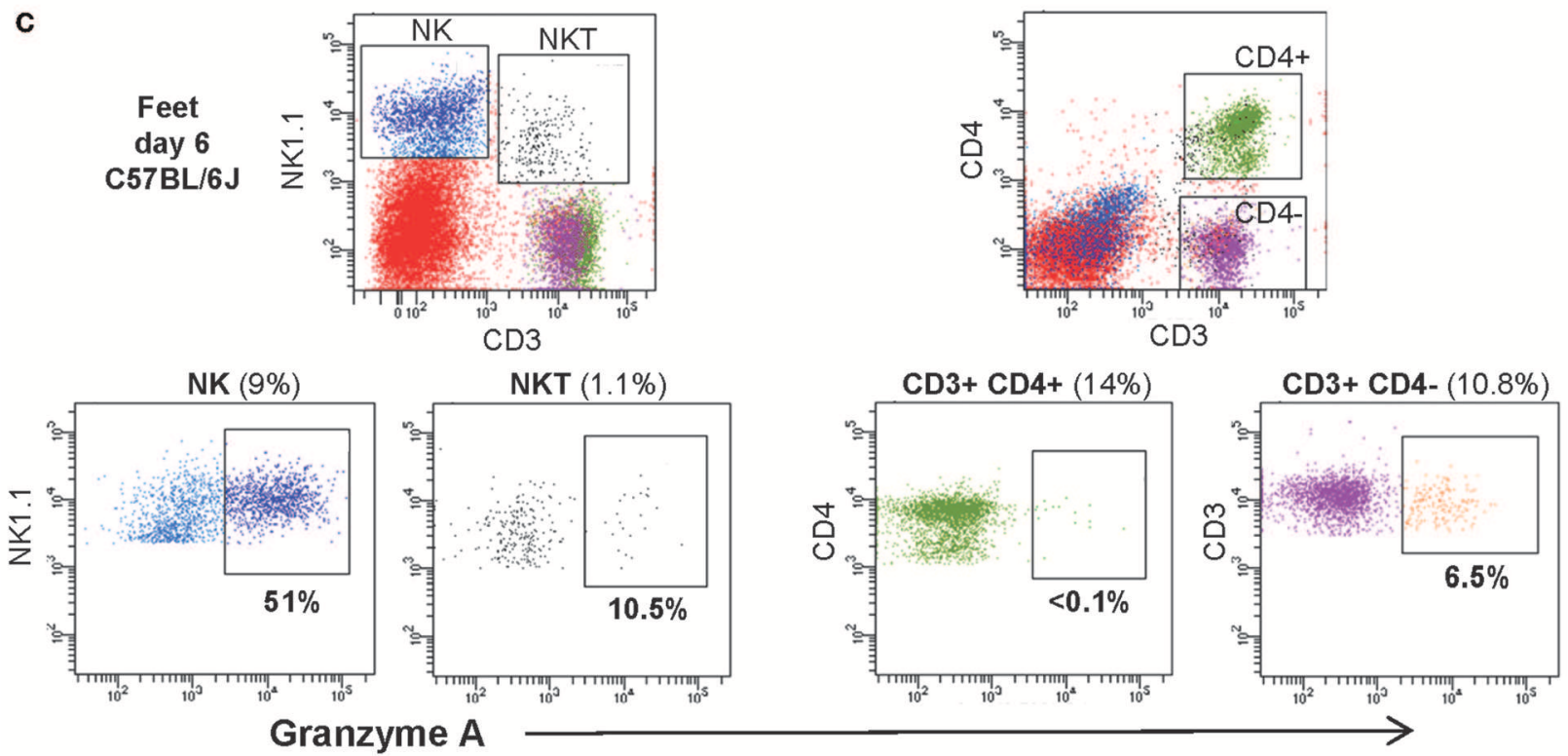

FIGURE 2 | Serum GzmA levels in CHIKV-infected adult wild-type mice. (A) C57BL/6 mice were infected with CHIKV and serum analyzed for GzmA by ELISA. Data from two independent experiments with 6-12 mice per time point. (B) Cells isolated from feet $(n=6-8)$ from CHIKV-infected C57BL/6 mice were pooled and analyzed by FACS for intracellular GzmA expression on day 2 post infection. Percentages in brackets are the \% of total live isolated cells from the feet. Percentages below the boxes are the percent of the indicted cell type that are GzmA positive. (C) Cells analyzed and gated as for B using cells isolated from feet 6 days post infection with CHIKV. 

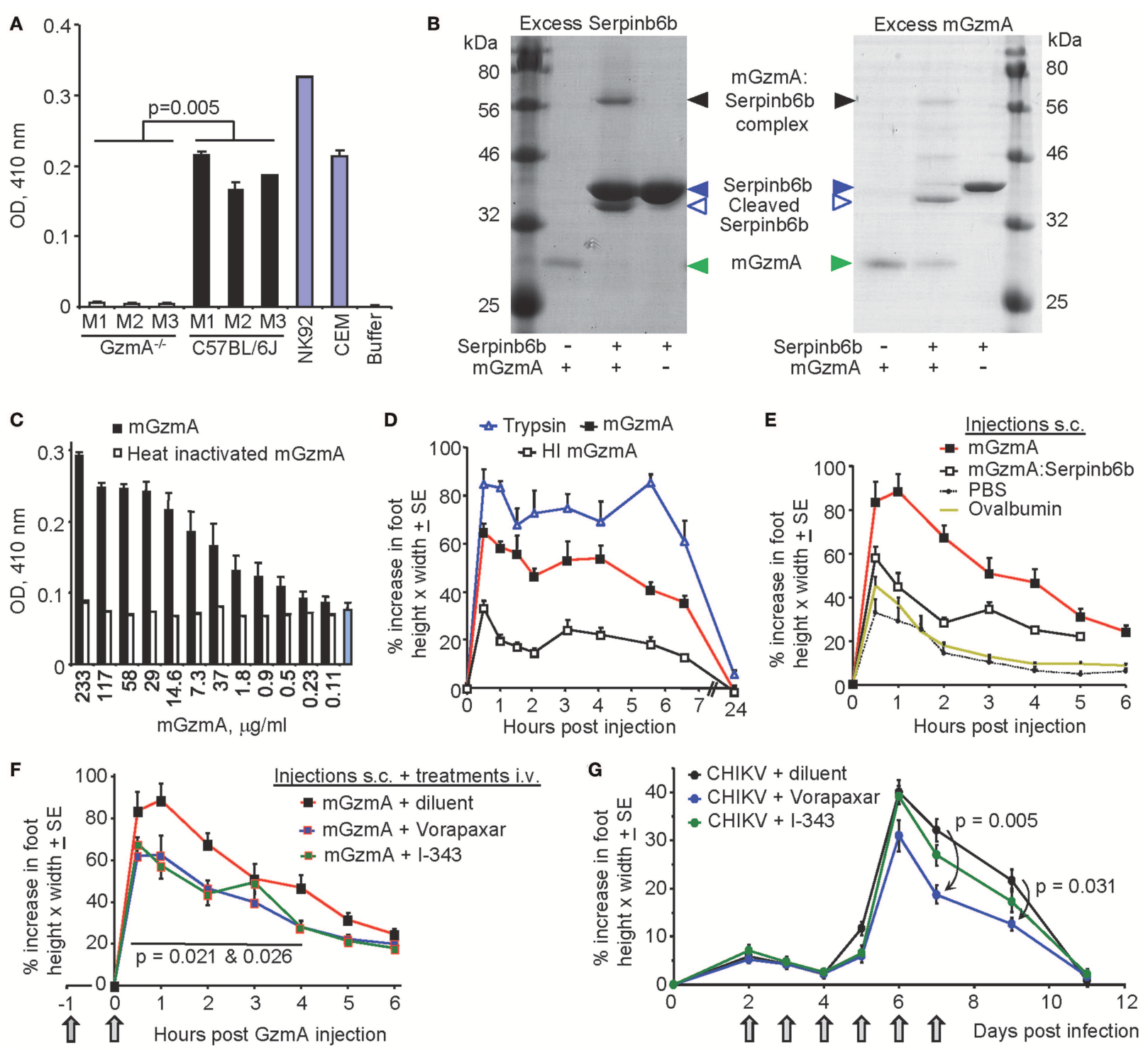

FIGURE 3 | Activity and bioactivity of mouse GzmA. (A) FACS-sorted NK cells from resting spleens were lysed, and lysates measured for BLT esterase activity in duplicate for 3 GzmA ${ }^{-1-}$ mice and 3 C57BL/6J mice. NK92 and CEM cell lines constitutively express GzmA and lysates from these lines were used as positive controls. Statistics by Kolmogorov Smirnov test using all replicates. (B) Recombinant mouse GzmA (mGzmA) and recombinant Serpinb6b were incubated together $\left(37^{\circ} \mathrm{C}\right.$ for $20 \mathrm{~min}$ ) either with a 6-fold molar excess of Serpinb6b (Excess Serpinb6b) or a 3-fold molar excess of mGzmA (Excess mGzmA). mGzmA, Serpinb6b, and complexes were then resolved by SDS-PAGE and stained with Coomassie Brilliant Blue. Some breakdown products of the complex are evident in Excess mGzmA. (C) BLT activity of $m G z m A$ and heat-inactivated $m G z m A$. The indicated concentrations of recombinant mGzmA and heat inactivated mGzmA were tested in duplicate in a BLT assay. The blue bar represents background BLT activity in the absence of any protein. (D) Injection (10 $\mu$ l) s.c. into feet of recombinant mGzmA (5 $\mu$ g), heat inactivated $\left(100^{\circ} \mathrm{C}, 1 \mathrm{~h}\right) \mathrm{mGzmA}(5 \mu \mathrm{g})$, or trypsin $(20 \mu \mathrm{g})(n=6$ mice per group). (E) Injection (30 $\mu \mathrm{l})$ s.c. into feet of mGzmA (5 $\left.\mu \mathrm{g}\right)$, mGzmA (5 $\left.\mu \mathrm{g}\right)$ complexed with $3.9 \mu \mathrm{g}$ recombinant Serpinb6b $\left(2: 1\right.$ molar ratio, $\left.1 \mathrm{~h} 37^{\circ} \mathrm{C}\right)$, ovalbumin $(8.9 \mu \mathrm{g})$ or PBS $(n=6$ mice per group). (F) The same experiment shown in $\mathrm{E}$ with two extra groups where mice injected with mGzmA were also treated at the indicated times (gray arrows) with Vorapaxar (20 $\mu \mathrm{g} / \mathrm{mouse}$ i.v. twice) or I-343 (20 $\mu \mathrm{g} / \mathrm{mouse}$ twice i.v.). The diluent control treatment was with DMF/PBS i.v. Repeat measure ANOVA from 0.5 to $4 \mathrm{~h}$ relative to diluent control Vorapaxar $p=0.026$, I-343 $p=0.021$. (G) Mice were infected with CHIKV as in Figure 2A and were treated with Vorapaxar or I-343 (10 $\mu \mathrm{g} / \mathrm{mouse}$ i.v. daily for 6 days) or diluent. The right and left foot was averaged for each mouse. Statistics by Kolmogorov Smirnov tests ( $n=6$ mice per group).

\section{Proteolytically Active GzmA Alone Is Sufficient for Inflammation Induction}

Injection of proteases subcutaneously (s.c.) into the feet of mice has been used as an assay to evaluate their pro-inflammatory activities (71-74). Injection of recombinant mGzmA s.c. into mouse feet resulted in significant foot swelling when compared with injection of heat-inactivated $\mathrm{mGzmA}$; trypsin was used as a positive control (71) (Figure 3D). This experiment was repeated with 2 additional controls (Figure 3E); (i) injection of ovalbumin (an equivalent $\mu \mathrm{g}$ dose 
of a proteolytically inactive foreign protein), which induced no increase in foot swelling over PBS, illustrating that the foot swelling was not simply due to injection of protein and (ii) injection of $\mathrm{mGzmA}$ complexed with Serpinb6b, which induced substantially lower foot swelling than $\mathrm{mGzmA}$, indicating that the (proteolytically inactive) Serpinb6b:mGzmA complex had limited proinflammatory activity in this assay.

Interestingly injection of recombinant $\mathrm{mGzmA}$ into one foot resulted in slight, but significant and similarly rapid, swelling in the contralateral foot (which had received no injections) (Supplementary Figure 3A). This suggested some injected mGzmA reached the other foot via the circulation and induced inflammation at the distant site.

\section{Treatment With Protease Activated Receptor 1 and 2 Antagonists}

GzmA has been reported to cleave PAR-1 (also known as the thrombin receptor) (24) and has been implicated in PAR-2 cleavage (26). Both PAR-1 and PAR-2 have been implicated in exacerbation of arthropathy $(75,76)$ and promotion of inflammation $(74,77)$. Mice injected subcutaneously with recombinant $\mathrm{mGzmA}$ were thus treated with the PAR-1 agonist Vorapaxar (78) and the PAR-2 antagonist I-343 (61). Both drug treatments provided a significant reduction in foot swelling in feet injected with mGzmA (Figure 3F). Vorapaxar and I-343 treatment also inhibited swelling of the contralateral feet (Supplementary Figure 3A). These data suggest that the pro-inflammatory activity of $\mathrm{mGzmA}$ involves (either directly or indirectly) PAR-1 and PAR-2. Note both drugs were
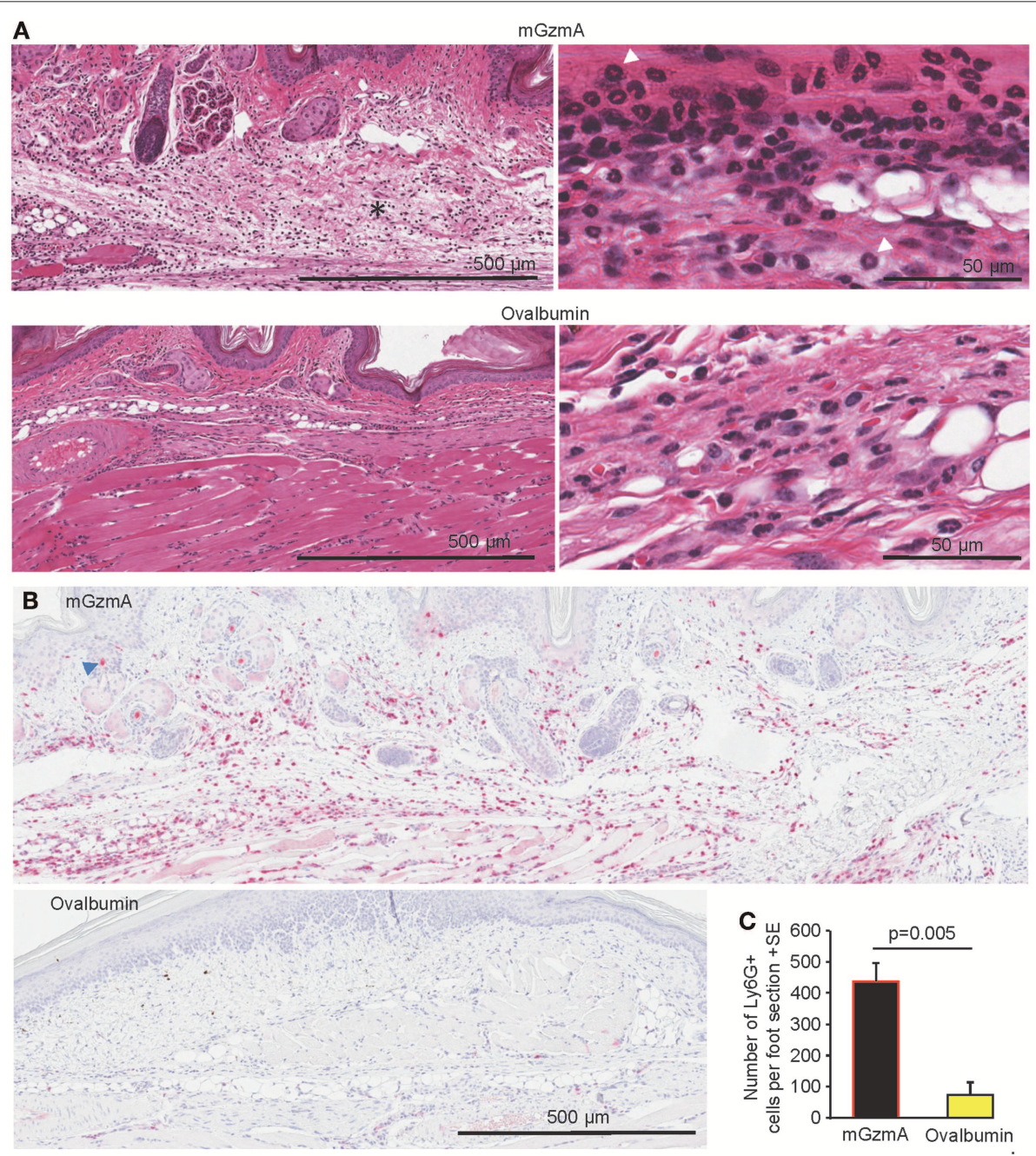

FIGURE 4 | Histology and IHC. (A) H\&E staining of feet sections taken 4 h after injection of mGzmA or ovalbumin (as in Figure $\mathbf{3 E}$ ). *indicates subcutaneous oedema surrounded by infiltrating cells. High resolution images are shown on the on the right. White arrowheads indicate examples of cells with polymorphonuclear morphology. (B) IHC staining with anti-Ly6G of foot sections taken $4 \mathrm{~h}$ after injection of mGzmA or ovalbumin (as for A). Neutrophils stain dark red (Warp Red). Pale red staining of hair follicles (blue arrowhead) is artifactual. (C) Quantitation of the IHC staining using 5/6 feet from 5/6 mice per group and the mean of 2/3 sections per foot. Statistics by Kolmogorov-Smirnov test ( $n=5 / 6$ per group). 
dissolved in dimethylformamide (DMF) rather than dimethyl sulfoxide (DMSO), to avoid the potentially confounding antiinflammatory activity of DMSO (79).

Vorapaxar and I-343 were also used to treat CHIKV arthritis. Treatment was started on day 2 post infection to minimize any effects on viraemia, which peaks at this time (54). Significant reductions in foot swelling were apparent on days 7 and 9 for Vorapaxar (Figure 3G), suggesting that PAR-1 is involved in CHIKV-induced inflammatory arthropathy. A repeat experiment is shown in Supplementary Figure 3B.

\section{Histology and Immunohistochemistry}

Histology was undertaken on feet $4 \mathrm{~h}$ after s.c. injection of recombinant $\mathrm{mGzmA}$ or ovalbumin. H\&E staining shows oedema and cellular infiltrates after mGzmA injection, which were substantially less apparent after ovalbumin injection (Figure 4A). Most of the infiltrating cells had a polymorphonuclear morphology (Figure $4 \mathrm{~A}$, top right). Immunohistochemical (IHC) staining with anti-Ly6G [a neutrophil specific marker (80)] revealed a higher number of neutrophils in the mGzmA group when compared to the ovalbumin group (Figure 4B). Quantitation of this IHC staining showed high significance (Figure 4C). (F4/80 staining was not significantly different, data not shown).

\section{GzmA Levels in Interferon-Deficient Mouse Models of Arboviral Infections}

$\mathrm{CHIKV}$ infection of mice deficient in interferon response factors 3 and 7 (IRF3/ $/ 7^{-/}$) provide a model of CHIKV hemorrhagic shock, with mice showing high viraemia (peaking on day 3 post infection), cytokinemia (high IFN $\gamma$, TNF, IL-6, peaking on day 2), fever (day 2), hypothermia (day 4-5), oliguria (day 4-5), thrombocytopenia (day 3-5), raised hematocrits (day 5), hemorrhage and mortality on day 4-6. GzmA levels peaked on day 2 post infection, reaching high levels (range $\approx 500-3,000$ $\mathrm{pg} / \mathrm{ml}$ ) that were on average $\approx 7$ fold higher in IRF3 $/ 7^{-/}$mice (Figure 5A) than those seen in wild-type mice (Figure 2A). The increase on days 5/6 may be associated with the hemoconcentration associated with hemorrhagic shock (55). mGzmA was again largely associated with NK cells in this model (Supplementary Figure 4). [Only splenocytes were available for analysis, as foot swelling in this model is not associated with a significant cellular infiltrate (55)]. Treatment with Serpinb6b did not provide significant protection against either foot swelling or mortality in this IRF3/7 ${ }^{-/}$model of hemorrhagic shock (Supplementary Figure 5).

Two ZIKV isolates $\mathrm{ZIKV}_{\text {Natal }}$ (an Asian genotype virus from Brazil) and $\mathrm{ZIKV}_{\mathrm{MR} 766}$ (a virulent African genotype virus) (57, $81,82)$ were used to infect type I interferon receptor deficient $\left(\mathrm{IFNAR}^{-/-}\right.$) mice and $\mathrm{IRF} 3 / 7^{-/-}$mice (83), respectively. Neither infection is lethal, with viraemia peaking day 2-3 post infection (at a mean of $\approx 3 \log _{10} \mathrm{CCID}_{50} / \mathrm{ml}$ ) for $\mathrm{ZIKV}_{\text {Natal }}(57)$ and day 2 post with a mean peak viraemia of $\approx 10^{5} \mathrm{CCID}_{50} / \mathrm{ml}$ for ZIKV ${ }_{\text {MR766 }}$ (56). High levels of $\mathrm{mGzmA}$ were seen, reaching means of $\approx 800$ and $\approx 1,200 \mathrm{pg} / \mathrm{ml}$, although the peak occurred later on day 6 for the less virulent $\mathrm{ZIKV}_{\text {Natal }}$ (Figure 5B).

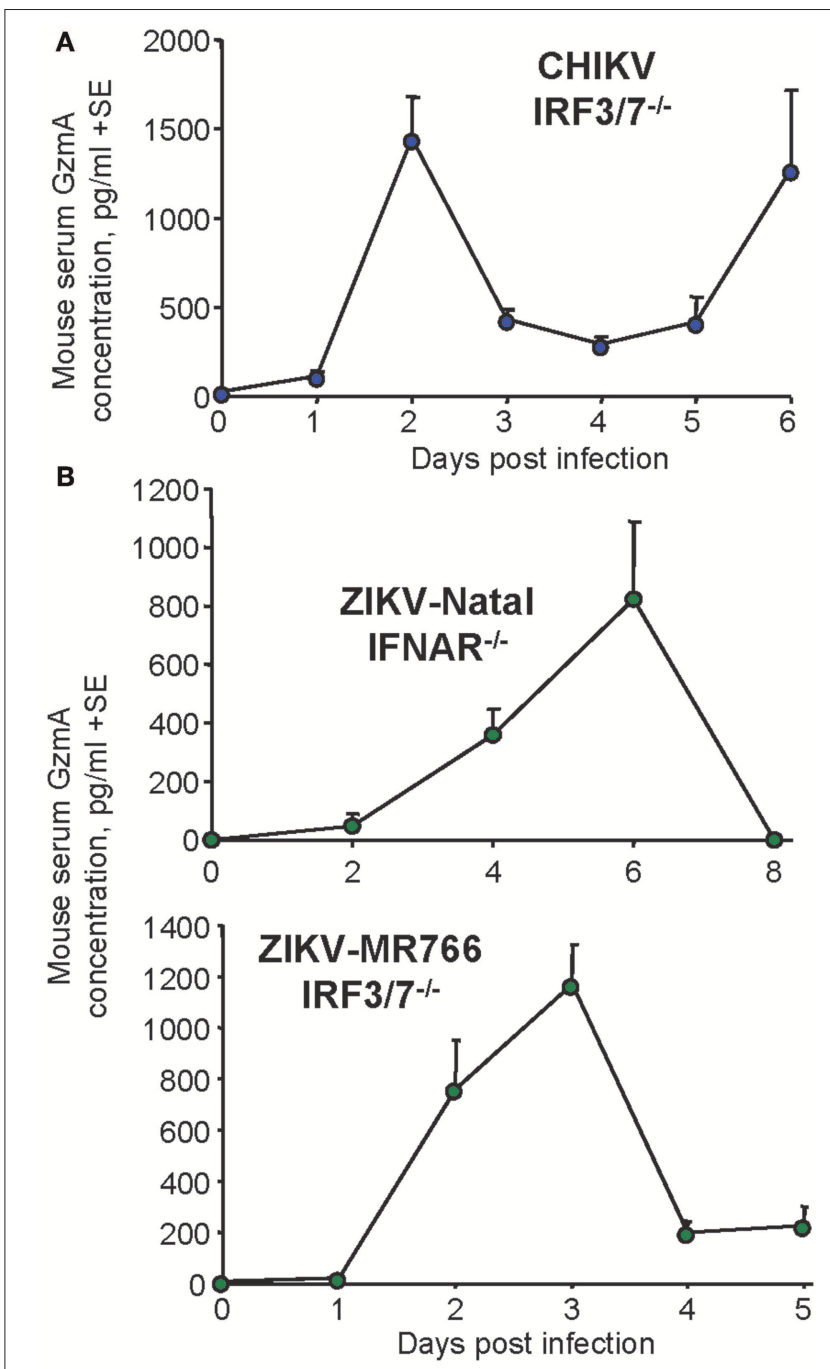

C

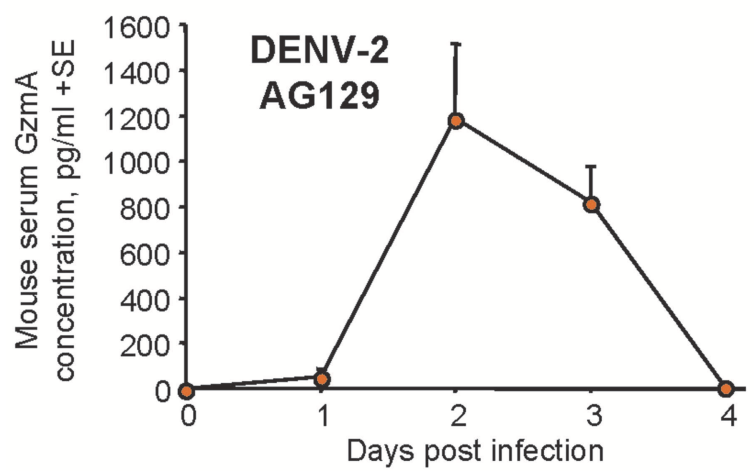

FIGURE 5 | Serum GzmA levels in type I IFN deficient mouse models of CHIKV, ZIKV and DENV (A) IRF3/7 $7^{-1-}$ mice were infected with CHIKV and serum analyzed for mGzmA by ELISA. Infection is lethal with mice euthanized day 5-6. Data from two independent experiments, with 6-12 mice per time point, except day 6 ( $n=4$; with 8 of 12 mice reaching ethically defined criteria requiring euthanasia). (B) IFNAR ${ }^{-1-}$ mice $(n=4)$ were infected with ZIKV-Natal (Asian genotype) and IRF3/7 $7^{-/-}$mice $(n=6)$ were infected with $10^{4} \mathrm{CCID}_{50}$ ZIKA-MR766 (African genotype) and serum samples analyzed for mGzmA levels. (C) AG129 mice ( $n=5$ ) infected with DENV-2 (D220), and serum samples analyzed for $\mathrm{mGzmA}$ levels. 
To investigate serum mGzmA levels in DENV infections, the well-established AG129 mouse model was used $(58,84)$. These mice have no type I or type II interferon receptors and inoculation with DENV-2 (strain D220, $10^{5} \mathrm{PFU}$, i.p.) results in viremia peaking day $2-3$ (at $10^{4}-10^{5} \mathrm{pfu} / \mathrm{ml}$ ), with euthanasia required around day 5 . On day 4 post infection animals exhibit significant vascular leakage (with limited hemorrhage) in several tissues (58). Early large increases in circulating $\mathrm{mGzmA}$ (reaching a mean of $\approx 1,200 \mathrm{pg} / \mathrm{ml}$ ) were again observed (Figure 5C).

\section{DISCUSSION}

We show here that circulating hGzmA levels are elevated during CHIKV disease in humans and that levels correlate with both viral load and disease severity. Using mouse models, we show that NK cells are the major source of $\mathrm{mGzmA}$, consistent with other studies in mice $(33,85)$. CD56+ NK cells have also been described in CHIKV patients $(46,47)$ and human CD56hi ${ }^{\text {NK }}$ cells have been shown to express high levels of hGzmA, with relatively low levels of perforin $(19,86)$. NK cells are part of the early innate anti-viral response to many virus infections (65), consistent with the early rise in serum hGzmA and $\mathrm{mGzmA}$ described herein. In wild-type mice infected with CHIKV, significant numbers of NK cells were also present in the early infiltrate day 2 post infection. Although NK cells have well-established anti-viral activity (65), mGzmA does not appear to mediate significant anti-viral activity against CHIKV (38). Nevertheless, NK cells have been implicated in inflammatory immunopathology in several settings (87-89), including CHIKV arthropathy (48) where mouse models suggest they may promote oedema (42). A pro-inflammatory role for NK-derived mGzmA has also been implicated in bacterial sepsis (90), with viral sepsis a rare but potentially fatal complication of acute CHIKV infection in humans (91).

The hGzmA levels reported herein ranged from 0 to $27 \mathrm{pg} / \mathrm{ml}$ (mean of $5.4 \pm \mathrm{SD} 6$ ) in a cohort of 56 Brazilian CHIKV patients, and ranged from 0 to $180 \mathrm{pg} / \mathrm{ml}$ (mean of $39.1 \pm \mathrm{SD}$ $70.9)$ in a previously reported small $(n=6) \mathrm{CHIKV}$ patient cohort comprising Australian visitors returned from overseas (38). GzmA levels in NHPs showed peak levels ranging from 80 to $370 \mathrm{pg} / \mathrm{ml}(n=9)(38)$. In C57BL/6 mice, peak levels on day 2 ranged from 40 to $554 \mathrm{pg} / \mathrm{ml}$ (averaging at $\approx 220 \mathrm{pg} / \mathrm{ml})(n=$ 12) (Figure 2A). hGzmA was reported to be present in the sera of 98 patients with dengue fever at a median level of $282 \mathrm{pg} / \mathrm{ml}$ (range 56-5,058), with healthy controls showing median levels of $15 \mathrm{pg} / \mathrm{ml}$ (range 3-124) (35). The latter study used an in-house ELISA and standards. hGzmA levels in CHIKV patients would thus appear to be somewhat lower compared with CHIKV animal models and DENV patients. However, reliable comparisons need to await (i) time series analyses post CHIKV infection to capture peak levels of hGzmA and (ii) formal cross-species validation of the relative performances of the different GzmA ELISA kits. Whether the aforementioned circulating serum concentrations of GzmA mediate significant or substantial bioactivity remains to be established. The ability of subcutaneously injected recombinant
mGzmA to mediate swelling on the contralateral foot, nominally argues that $<5 \mu \mathrm{g} / \mathrm{ml}$ of $\mathrm{mGzmA}$ ( $5 \mu \mathrm{g}$ injected, with a mouse blood volume of $\approx 1 \mathrm{ml}$ ) is systemically overtly bioactive, with this concentration reportedly seen in some DENV patients (35).

Circulating hGzmA appears to remain largely proteolytically active (92). PAR-1 and PAR-2 cleavage by mGzmA have been implicated herein and elsewhere as a mechanism whereby mGzmA promotes inflammation $(24,26)$. However, we are currently undertaking detailed molecular studies to determine if GzmA cleaves PAR-1 and/or PAR-2 under physiological conditions, rather than PAR-1 and/or PAR-2 being involved somewhere in the GzmA- or CHIKV-induced pro-inflammatory cascades. There are $>550$ proteases in the mouse and human genomes (93), with PAR1/2 cleaved by many different inflammation-associated proteases (77) including granzyme $\mathrm{K}$ $(38,94,95)$. PAR $1 / 2$ have also been shown to be involved in a range of mouse models of arthritis (76, 96-98), suggesting their widespread involvement in this type of immunopathology. The role of neutrophils in mGzmA-mediated foot swelling and its inhibition by PAR1/2-antagonists is consistent with the known involvement of PAR-1 and PAR-2 in neutrophilassociated inflammation $(73,99,100)$. However, alphaviral arthritides generally have few neutrophils $(51,101,102)$ arguing that other factors are in play, or that the presence of other proteases or inflammatory activities modulate mGzmA activity during CHIKV arthritis. Unraveling the role of PAR1/2 is also complicated by the ability of certain proteases [including hGzmA (25)] to induce biased signaling, whereby some but not other inflammatory pathways are activated $(72,74,103,104)$. In addition, there are distinct differences between $\mathrm{mGzmA}$ and hGzmA (31, 105), with mice (but not humans) also encoding the specific $\mathrm{mGzmA}$ inhibitor (Serpinb6b) which is expressed by resolution phase macrophages during CHIKV arthritis (101).

What might be the physiological function (if any) of the rapid early post-infection rise in circulating GzmA? As two other granule components, perforin and GzmB, can also be found in the circulation $(106,107)$, serum GzmA may simply represent a by-product of the anti-viral responses of activated NK cells and other cytotoxic lymphocytes. Circulating GzmA could thus be viewed as a systemic biomarker for cytotoxic lymphocyte activity somewhere in the body. However, we show herein, for the first time, that injection of purified recombinant $\mathrm{mGzmA}$ was able to mediate acute inflammation, both locally and in the contralateral foot, arguing that circulating GzmA may function to distribute proinflammatory activity systemically $(12,15)$. Conceivably, circulating GzmA might act as an "danger signal" or alarmin (29), providing systemic notification (in the current setting) of the engagement of NK cells with arbovirus infected cells. Increased circulating $\mathrm{mGzmA}$ levels in IFN deficient mice may thereby reflect increased "danger," given the lack of protective IFN activities and high viral loads. The lack of significant inflammatory activity mediated by the $\mathrm{mGzmA}$ :Serpinb6b complex argues that $\mathrm{mGzmA}$ 's protease activity is required for its pro-inflammatory activity. This argument would clearly be strengthened if we had a better understanding of the molecular mechanism(s) responsible for GzmA’s pro-inflammatory activity. 
Th1 CD4 T cells are thought to be the major drivers of CHIKV arthritic disease $(40,43,51)$. GzmA-expressing CD4 CTL have been identified in several viral infections (HIV, CMV, vaccinia, DENV) $(6,108)$ and in rheumatoid arthritis (6). However, we found no evidence that CHIKV infection induces expression of $\mathrm{mGzmA}$ in CD4 T cells. To the best of our knowledge, there are no studies showing CHIKV-specific CD4 T cells to be cytotoxic or to express significant levels of GzmA. GzmA secretion by Th1 CD4 T cells is thus unlikely to be a major driver of CHIKV arthritis. Conceivably, NK-derived GzmA might promote CD4 $\mathrm{T}$ cell activation via activation of antigen presenting cells $(20,29,109)$.

The ability of Vorapaxar to inhibit CHIKV-induced foot swelling might argue that PAR-1 is a potential new target for anti-inflammatory treatment of alphaviral arthritides. However, in humans Vorapaxar is generally used to inhibit PAR-1 on platelets (110), with PAR-1 not expressed on mouse platelets. Given that hemorrhagic manifestations are uncommon, but welldocumented, during acute CHIKV infections, platelet inhibition would not be recommended; especially if there was a possibility that the patient had a DENV infection (51). Even if biased PAR1 antagonists $(74,103)$ could be developed that did not inhibit platelet function (25), the very rapid early rise in GzmA levels post-infection likely also leaves an unrealistically narrow window between diagnosis and treatment initiation. Given the role of PAR-2 in persistent pain (61) another avenue potentially worthy of investigation is the treatment of persistent CHIKV arthralgia (51) with PAR-2 antagonists; however, an animal model in which chronic CHIKV joint pain can be readily monitored has yet to be developed.

In summary raised levels of circulating GzmA are evident in acute infections of medically important arboviruses, and recombinant $\mathrm{mGzmA}$ was by itself able to mediate inflammation. Although PAR-1 and PAR-2 antagonists appear, at least partially, to inhibit foot swelling induced by $\mathrm{mGzmA}$ injection, a physiological role for GzmA in direct PAR1/2 cleavage and signaling has yet to be established.

\section{DATA AVAILABILITY STATEMENT}

All datasets generated for this study are included in the article/Supplementary Material.

\section{ETHICS STATEMENT}

For samples collected in Sergipe and São Paulo, human studies were approved by the ethics committee (CEPSH/ICB) of the Instituto de Ciências Biomédicas da Universidade de São Paulo (ICB-USP) (Authorization \#1284/CEPSH-CAAE: 54937216.5.0000.5467 e CAAE: 61551116.3.0000.5553). The samples are part of a registered biorepository under the custody of PZ, who authorized their use in the studies described herein. For samples collected in Brasília, human studies were approved by the Ethics Committee of Secretaria de Estado de Saúde do Distrito Federal (FEPECS/SES/DF) (CAAE:
36249214.0.0000.5553). The samples were part of the Laboratório Central de Saúde Pública do DF (LACEN-DF) biorepository and permission for their use for measuring granzyme levels was provided by LACEN-DF. All serum sample donors signed a consent form. Mouse work was conducted in accordance with the Australian code for the care and use of animals for scientific purposes as defined by the National Health and Medical Research Council of Australia. Mouse work was approved by the QIMR Berghofer Medical Research Institute animal ethics committee (P2195, A1604-611M, and P1060 A705603M). Dengue work was also approved by the University of Queensland Animal Ethics Committee.

\section{AUTHOR CONTRIBUTIONS}

ASS, DB, CS, PMAZ, and KM: obtained the clinical samples and data and undertook the human analyses. TL, DK, CR, and NP: undertook the other experiments. LA, DM, and PY: provided vital reagents and samples. PZ, PB, NP, and AS: funding acquisition. ASS, AS, and PB: conceptualized the study. AS: wrote the manuscript with input from PB, ASS, TL, and NP.

\section{FUNDING}

The work in Brazil was supported by Butantan Foundation, CNPq (Grant 443371/2016-4) and FAPDF/PPSUS \# 193.001.621/2016. The work in Australia was supported by a project grant from the National Health and Medical Research Council (NHMRC) of Australia (APP1078468) and intramural seed funding from the Australian Infectious Disease Research Center. NP was supported by an Advance Queensland Research Fellowship from the Queensland Government, Australia. AS holds a Principal Research Fellowship from the National Health and Medical Research Council of Australia.

\section{ACKNOWLEDGMENTS}

We thank the QIMR B animal house staff for their assistance and Clay Winterford and his team at QIMR B for their help with histology and immunohistochemistry. We thank Dr. I. Anraku for his assistance in managing the BSL3 facility at QIMR B. We thank Dr. Danuza Duarte Costa from Health Foundation Parreiras Horta (FSPH), Central Laboratory of Public Health (LACEN/SE) for sample collection organization. We also thank Dr. Nigel W. Bunnett (Columbia University College of Physicians and Surgeons, Columbia University, New York, USA) for his invaluable help with grant writing and insights into PAR biology.

\section{SUPPLEMENTARY MATERIAL}

The Supplementary Material for this article can be found online at: https://www.frontiersin.org/articles/10.3389/fimmu. 2019.03083/full\#supplementary-material 


\section{REFERENCES}

1. Wu CH, Li J, Li L, Sun J, Fabbri M, Wayne AS, et al. Extracellular vesicles derived from natural killer cells use multiple cytotoxic proteins and killing mechanisms to target cancer cells. J Extracell Vesicles. (2019) 8:1588538. doi: 10.1080/20013078.2019.1588538

2. Fehniger TA, Cai SF, Cao X, Bredemeyer AJ, Presti RM, French AR, et al. Acquisition of murine NK cell cytotoxicity requires the translation of a pre-existing pool of granzyme B and perforin mRNAs. Immunity. (2007) 26:798-811. doi: 10.1016/j.immuni.2007.04.010

3. Gordy LE, Bezbradica JS, Flyak AI, Spencer CT, Dunkle A, Sun J, et al. IL15 regulates homeostasis and terminal maturation of NKT cells. J Immunol. (2011) 187:6335-45. doi: 10.4049/jimmunol.1003965

4. Suhrbier A, Fernan A, Burrows SR, Saul A, Moss DJ. BLT esterase activity as an alternative to chromium release in cytotoxic T cell assays. J Immunol Methods. (1991) 145:43-53. doi: 10.1016/0022-1759(91)90309-4

5. Della-Torre E, Bozzalla-Cassione E, Sciorati C, Ruggiero E, Lanzillotta M, Bonfiglio S, et al. A CD8alpha- subset of CD4+SLAMF7+ cytotoxic $\mathrm{T}$ cells is expanded in patients with IgG4-related disease and decreases following glucocorticoid treatment. Arthritis Rheumatol. (2018) 70:113343. doi: $10.1002 /$ art.40469

6. Silveira GF, Wowk PF, Cataneo AHD, Dos Santos PF, Delgobo M, Stimamiglio MA, et al. Human T lymphocytes are permissive for dengue virus replication. J Virol. (2018) 92:e02181-17. doi: 10.1128/JVI.02181-17

7. Muraro E, Merlo A, Martorelli D, Cangemi M, Dalla Santa S, Dolcetti R, et al. Fighting viral infections and virus-driven tumors with cytotoxic CD4(+) T cells. Front Immunol. (2017) 8:197. doi: 10.3389/fimmu.2017.00197

8. Liesche C, Sauer P, Prager I, Urlaub D, Claus M, Eils R, et al. Singlefluorescent protein reporters allow parallel quantification of natural killer cell-mediated granzyme and caspase activities in single target cells. Front immunol. (2018) 9:1840. doi: 10.3389/fimmu.2018.01840

9. Mpande CAM, Dintwe OB, Musvosvi M, Mabwe S, Bilek N, Hatherill M, et al. Functional, antigen-specific stem cell memory (TSCM) CD4(+) T cells are induced by human Mycobacterium tuberculosis infection. Front immunol. (2018) 9:324. doi: 10.3389/fimmu.2018.00324

10. Golstein P, Griffiths GM. An early history of T cell-mediated cytotoxicity. Nat Rev Immunol. (2018) 18:527-35. doi: 10.1038/s41577-018-0009-3

11. Joeckel LT, Bird PI. Are all granzymes cytotoxic in vivo? Biol Chem. (2014) 395:181-202. doi: 10.1515/hsz-2013-0238

12. Wensink AC, Hack CE, Bovenschen N. Granzymes regulate proinflammatory cytokine responses. J Immunol. (2015) 194:4917. doi: 10.4049/jimmunol.1401214

13. Metkar SS, Menaa C, Pardo J, Wang B, Wallich R, Freudenberg M, et al. Human and mouse granzyme A induce a proinflammatory cytokine response. Immunity. (2008) 29:720-33. doi: 10.1016/j.immuni.2008.08.014

14. Campbell RA, Franks Z, Bhatnagar A, Rowley JW, Manne BK, Supiano $\mathrm{MA}$, et al. Granzyme A in human platelets regulates the synthesis of proinflammatory cytokines by monocytes in aging. I Immunol. (2018) 200:295-304. doi: 10.4049/jimmunol.1700885

15. Kiniry BE, Hunt PW, Hecht FM, Somsouk M, Deeks SG, Shacklett BL. Differential expression of $\mathrm{CD} 8(+) \mathrm{T}$ cell cytotoxic effector molecules in blood and gastrointestinal mucosa in HIV-1 infection. J Immunol. (2018) 200:1876-88. doi: 10.4049/jimmunol.1701532

16. Santiago L, Menaa C, Arias M, Martin P, Jaime-Sanchez P, Metkar S, et al. Granzyme A contributes to inflammatory arthritis in mice through stimulation of osteoclastogenesis. Arthritis Rheumatol. (2017) 69:32034. doi: 10.1002/art.39857

17. Chemin K, Gerstner C, Malmstrom V. Effector functions of CD4+ T cells at the site of local autoimmune inflammation-lessons from rheumatoid arthritis. Front Immunol. (2019) 10:353. doi: 10.3389/fimmu.2019.00353

18. Cheuk S, Martini E, Bergh K, Chang D, Rethi B, Stahle M, et al. Granzyme A potentiates chemokine production in IL-17-stimulated keratinocytes. Exp Dermatol. (2017) 26:824-7. doi: 10.1111/exd.13284

19. Jaime P, Garcia-Guerrero N, Estella R, Pardo J, Garcia-Alvarez F, Martinez-Lostao L. CD56(+)/CD16(-) Natural Killer cells expressing the inflammatory protease granzyme A are enriched in synovial fluid from patients with osteoarthritis. Osteoarthritis Cartilage. (2017) 25:170818. doi: $10.1016 /$ j.joca.2017.06.007
20. Hildebrand D, Bode KA, Riess D, Cerny D, Waldhuber A, Rommler F, et al. Granzyme A produces bioactive IL-1beta through a nonapoptotic inflammasome-independent pathway. Cell Rep. (2014) 9:910-7. doi: 10.1016/j.celrep.2014.10.003

21. Mandrup-Poulsen T. Granzyme A in the pathogenesis of type 1 diabetes: the yes and the no. Diabetes. (2017) 66:2937-9. doi: 10.2337/dbi17-0037

22. Mollah ZUA, Quah HS, Graham KL, Jhala G, Krishnamurthy B, Dharma JFM, et al. Granzyme A deficiency breaks immune tolerance and promotes autoimmune diabetes through a type I interferon-dependent pathway. Diabetes. (2017) 66:3041-50. doi: 10.2337/db17-0517

23. Brunner G, Simon MM, Kramer MD. Activation of pro-urokinase by the human T cell-associated serine proteinase HuTSP-1. FEBS Lett. (1990) 260:141-4. doi: 10.1016/0014-5793(90)80087-Y

24. Suidan HS, Bouvier J, Schaerer E, Stone SR, Monard D, Tschopp J. Granzyme A released upon stimulation of cytotoxic $\mathrm{T}$ lymphocytes activates the thrombin receptor on neuronal cells and astrocytes. Proc Natl Acad Sci USA. (1994) 91:8112-6. doi: 10.1073/pnas.91.17.8112

25. Suidan HS, Clemetson KJ, Brown-Luedi M, Niclou SP, Clemetson JM, Tschopp J, et al. The serine protease granzyme A does not induce platelet aggregation but inhibits responses triggered by thrombin. Biochem J. (1996) 315 (Pt 3):939-45. doi: 10.1042/bj3150939

26. Hansen KK, Sherman PM, Cellars L, Andrade-Gordon P, Pan Z, Baruch A, et al. A major role for proteolytic activity and proteinase-activated receptor2 in the pathogenesis of infectious colitis. Proc Natl Acad Sci USA. (2005) 102:8363-8. doi: 10.1073/pnas.0409535102

27. Sower LE, Froelich CJ, Allegretto N, Rose PM, Hanna WD, Klimpel GR. Extracellular activities of human granzyme A. Monocyte activation by granzyme A versus alpha-thrombin. J Immunol. (1996) 156:258590. doi: 10.1006/cimm.1996.0187

28. van Eck JA, Shan L, Meeldijk J, Hack CE, Bovenschen N. A novel proinflammatory role for granzyme A. Cell Death Dis. (2017) 8:e2630. doi: 10.1038/cddis.2017.56

29. Shimizu K, Yamasaki S, Sakurai M, Yumoto N, Ikeda M, MishimaTsumagari C, et al. Granzyme A stimulates pDCs to promote adaptive immunity via induction of type I IFN. Front immunol. (2019) 10:1450. doi: 10.3389/fimmu.2019.01450

30. Velaga S, Ukena SN, Dringenberg U, Alter C, Pardo J, Kershaw $\mathrm{O}$, et al. Granzyme A is required for regulatory T-cell mediated prevention of gastrointestinal graft-versus-host disease. PLOS ONE. (2015) 10:e0124927. doi: 10.1371/journal.pone.0124927

31. Kaiserman D, Stewart SE, Plasman K, Gevaert K, Van Damme P, Bird PI. Identification of Serpinb6b as a species-specific mouse granzyme A inhibitor suggests functional divergence between human and mouse granzyme A. J Biol Chem. (2014) 289:9408-17. doi: 10.1074/jbc.M113.525808

32. Stables MJ, Shah S, Camon EB, Lovering RC, Newson J, Bystrom J, et al. Transcriptomic analyses of murine resolution-phase macrophages. Blood. (2011) 118:e192-208. doi: 10.1182/blood-2011-04-345330

33. Garcia-Laorden MI, Stroo I, Terpstra S, Florquin S, Medema JP, van TVC, et al. Expression and function of granzymes A and B in Escherichia coli peritonitis and sepsis. Mediators Inflamm. (2017) 2017:4137563. doi: 10.1155/2017/4137563

34. de Jong HK, Garcia-Laorden MI, Hoogendijk AJ, Parry CM, Maude RR, Dondorp AM, et al. Expression of intra- and extracellular granzymes in patients with typhoid fever. PLoS Negl Trop Dis. (2017) 11:e0005823. doi: 10.1371/journal.pntd.00 05823

35. Spaeny-Dekking EH, Kamp AM, Froelich CJ, Hack CE. Extracellular granzyme A, complexed to proteoglycans, is protected against inactivation by protease inhibitors. Blood. (2000) 95:146572. doi: 10.1182/blood.V95.4.1465.004k13_1465_1472

36. Hermsen CC, Konijnenberg Y, Mulder L, Loe C, van Deuren M, van der Meer JW, et al. Circulating concentrations of soluble granzyme A and B increase during natural and experimental Plasmodium falciparum infections. Clin Exp Immunol. (2003) 132:467-72. doi: 10.1046/j.1365-2249.2003.02160.x

37. Lauw FN, Simpson AJ, Hack CE, Prins JM, Wolbink AM, van Deventer SJ, et al. Soluble granzymes are released during human endotoxemia and in patients with severe infection due to gram-negative bacteria. J Infect Dis. (2000) 182:206-13. doi: 10.1086/315642 
38. Wilson JA, Prow NA, Schroder WA, Ellis JJ, Cumming HE, Gearing LJ, et al. RNA-Seq analysis of chikungunya virus infection and identification of granzyme A as a major promoter of arthritic inflammation. PLoS Pathog. (2017) 13:e1006155. doi: 10.1371/journal.ppat.10 06155

39. Mullbacher A, Ebnet K, Blanden RV, Hla RT, Stehle T, Museteanu C, et al. Granzyme A is critical for recovery of mice from infection with the natural cytopathic viral pathogen, ectromelia. Proc Natl Acad Sci USA. (1996) 93:5783-7. doi: 10.1073/pnas.93.12.5783

40. Teo TH, Lum FM, Claser C, Lulla V, Lulla A, Merits A, et al. A pathogenic role for $\mathrm{CD} 4+\mathrm{T}$ cells during chikungunya virus infection in mice. J Immunol. (2013) 190:259-69. doi: 10.4049/jimmunol.12 02177

41. Burrack KS, Montgomery SA, Homann D, Morrison TE. CD8+ T cells control Ross River virus infection in musculoskeletal tissues of infected mice. J Immunol. (2015) 194:678-89. doi: 10.4049/jimmunol.14 01833

42. Poo YS, Rudd PA, Gardner J, Wilson JA, Larcher T, Colle MA, et al. Multiple immune factors are involved in controlling acute and chronic chikungunya virus infection. PLoS Negl Trop Dis. (2014) 8:e3354. doi: 10.1371/journal.pntd.0003354

43. Nakaya HI, Gardner J, Poo YS, Major L, Pulendran B, Suhrbier A. Gene profiling of Chikungunya virus arthritis in a mouse model reveals significant overlap with rheumatoid arthritis. Arthritis Rheum. (2012) 64:3553-63. doi: 10.1002/art.34631

44. Gasque P, Jaffar-Bandjee MC. Blunting CHIKV infection by keeping $\mathrm{T}$ cells in check. Sci Transl Med. (2017) 9:eaam6567. doi: 10.1126/scitranslmed.aam6567

45. Teo TH, Chan YH, Lee WW, Lum FM, Amrun SN, Her Z, et al. Fingolimod treatment abrogates chikungunya virus-induced arthralgia. Sci Transl Med. (2017) 9:eaal1333. doi: 10.1126/scitranslmed.aa 11333

46. Hoarau JJ, Bandjee MCJ, Trotot PK, Das T, Li-Pat-Yuen G, Dassa B, et al. Persistent chronic inflammation and infection by chikungunya arthritogenic alphavirus in spite of a robust host immune response. J Immunol. (2010) 184:5914-27. doi: 10.4049/jimmunol.0900255

47. Petitdemange C, Becquart P, Wauquier N, Beziat V, Debre P, Leroy $\mathrm{EM}$, et al. Unconventional repertoire profile is imprinted during acute chikungunya infection for natural killer cells polarization toward cytotoxicity. PLoS Pathog. (2011) 7:e1002268. doi: 10.1371/journal.ppat.10 02268

48. Teo TH, Her Z, Tan JJ, Lum FM, Lee WW, Chan YH, et al. Caribbean and La Reunion chikungunya virus isolates differ in their capacity to induce proinflammatory Th1 and NK cell responses and acute joint pathology. $J$ Virol. (2015) 89:7955-69. doi: 10.1128/JVI.00909-15

49. Petitdemange C, Wauquier N, Devilliers H, Yssel H, Mombo I, Caron $\mathrm{M}$, et al. Longitudinal analysis of natural killer cells in dengue virus-infected patients in comparison to chikungunya and chikungunya/dengue virus-infected patients. PLoS Negl Trop Dis. (2016) 10:e0004499. doi: 10.1371/journal.pntd.0004499

50. Thanapati S, Ganu M, Giri P, Kulkarni S, Sharma M, Babar P, et al. Impaired NK cell functionality and increased TNF-alpha production as biomarkers of chronic chikungunya arthritis and rheumatoid arthritis. Hum Immunol. (2017) 78:370-4. doi: 10.1016/j.humimm.2017.02.006

51. Suhrbier A. Rheumatic manifestations of chikungunya: emerging concepts and interventions. Nat Rev Rheumatol. (2019) 15:597611. doi: 10.1038/s41584-019-0276-9

52. Cunha MDP, Santos CAD, Neto DFL, Schanoski AS, Pour SZ, Passos $\mathrm{SD}$, et al. Outbreak of chikungunya virus in a vulnerable population of Sergipe, Brazil-A molecular and serological survey. J Clin Virol. (2017) 97:44-9. doi: 10.1016/j.jcv.2017.10.015

53. Soares-Schanoski A, Baptista Cruz N, de Castro-Jorge LA, de Carvalho RVH, Santos CAD, Ros ND, et al. Systems analysis of subjects acutely infected with the Chikungunya virus. PLoS Pathog. (2019) 15:e1007880. doi: 10.1371/journal.ppat.1007880

54. Gardner J, Anraku I, Le TT, Larcher T, Major L, Roques P, et al. Chikungunya virus arthritis in adult wild-type mice. J Virol. (2010) 84:802132. doi: 10.1128/JVI.02603-09
55. Rudd PA, Wilson J, Gardner J, Larcher T, Babarit C, Le TT, et al. Interferon response factors 3 and 7 protect against chikungunya virus hemorrhagic fever and shock. J Virol. (2012) 86:9888-98. doi: 10.1128/JVI.00956-12

56. Prow NA, Liu L, Nakayama E, Cooper TH, Yan K, Eldi P, et al. A vaccinia-based single vector construct multi-pathogen vaccine protects against both Zika and chikungunya viruses. Nat Commun. (2018) 9:1230. doi: 10.1038/s41467-018-03662-6

57. Setoh YX, Prow NA, Peng N, Hugo LE, Devine G, Hazlewood JE, et al. De novo generation and characterization of new Zika virus isolate using sequence data from a microcephaly case. mSphere. (2017) 2:e0019017. doi: 10.1128/mSphereDirect.00190-17

58. Modhiran N, Watterson D, Muller DA, Panetta AK, Sester DP, Liu L, et al. Dengue virus NS1 protein activates cells via Toll-like receptor 4 and disrupts endothelial cell monolayer integrity. Sci Transl Med. (2015) 7:304ra142. doi: 10.1126/scitranslmed.aaa3863

59. Sun J, Bird CH, Buzza MS, McKee KE, Whisstock JC, Bird PI. Expression and purification of recombinant human granzyme B from Pichia pastoris. Biochem Biophys Res Commun. (1999) 261:251-5. doi: 10.1006/bbrc.1999.0989

60. Susanto O, Stewart SE, Voskoboinik I, Brasacchio D, Hagn M, Ellis S, et al. Mouse granzyme A induces a novel death with writhing morphology that is mechanistically distinct from granzyme B-induced apoptosis. Cell Death Differ. (2013) 20:1183-93. doi: 10.1038/cdd.2013.59

61. Jimenez-Vargas NN, Pattison LA, Zhao P, Lieu T, Latorre R, Jensen DD, et al. Protease-activated receptor-2 in endosomes signals persistent pain of irritable bowel syndrome. Proc Natl Acad Sci USA. (2018) 115:E7438E47. doi: 10.1073/pnas.1721891115

62. Triggianese P, Perricone C, Conigliaro P, Chimenti MS, Perricone R, De Carolis C. Peripheral blood natural killer cells and mild thyroid abnormalities in women with reproductive failure. Int $J$ Immunopathol Pharmacol. (2016) 29:65-75. doi: 10.1177/03946320156 15130

63. Michlmayr D, Pak TR, Rahman AH, Amir ED, Kim EY, Kim-Schulze S, et al. Comprehensive innate immune profiling of chikungunya virus infection in pediatric cases. Mol Syst Biol. (2018) 14:e7862. doi: 10.15252/msb.20177862

64. Webster B, Werneke SW, Zafirova B, This S, Coleon S, Decembre E, et al. Plasmacytoid dendritic cells control dengue and Chikungunya virus infections via IRF7-regulated interferon responses. Elife. (2018) 7:e34273. doi: 10.7554/eLife.34273.022

65. Hammer Q, Ruckert T, Romagnani C. Natural killer cell specificity for viral infections. Nat Immunol. (2018) 19:800-8. doi: 10.1038/s41590-018-0163-6

66. Linn ML, Mateo L, Gardner J, Suhrbier A. Alphavirus-specific cytotoxic $\mathrm{T}$ lymphocytes recognize a cross-reactive epitope from the capsid protein and can eliminate virus from persistently infected macrophages. $J$ Virol. (1998) 72:5146-53.

67. Liu J, Hill BJ, Darko S, Song K, Quigley MF, Asher TE, et al. The peripheral differentiation of human natural killer T cells. Immunol Cell Biol. (2019) 97:586-96. doi: 10.1111/imcb.12248

68. Thanapati S, Ganu MA, Tripathy AS. Differential inhibitory and activating NK cell receptor levels and NK/NKT-like cell functionality in chronic and recovered stages of chikungunya. PLoS ONE. (2017) 12:e0188342. doi: 10.1371/journal.pone.01 88342

69. Stewart SE, D’Angelo ME, Bird PI. Intercellular communication via the endo-lysosomal system: translocation of granzymes through membrane barriers. Biochim Biophys Acta. (2012) 1824:59-67. doi: 10.1016/j.bbapap.2011.05.020

70. Sun J, Coughlin P, Salem HH, Bird P. Production and characterization of recombinant human proteinase inhibitor 6 expressed in Pichia pastoris. Biochim Biophys Acta. (1995) 1252:28-34. doi: 10.1016/0167-4838(95)00108-7

71. Suen JY, Barry GD, Lohman RJ, Halili MA, Cotterell AJ, Le GT, et al. Modulating human proteinase activated receptor 2 with a novel antagonist (GB88) and agonist (GB110). Br J Pharmacol. (2012) 165:141323. doi: 10.1111/j.1476-5381.2011.01610.x

72. Zhao P, Lieu T, Barlow N, Metcalf M, Veldhuis NA, Jensen DD, et al. Cathepsin S causes inflammatory pain via biased agonism of PAR2 and TRPV4. J Biol Chem. (2014) 289:27215-34. doi: 10.1074/jbc.M114.599712 
73. Zhao P, Lieu T, Barlow N, Sostegni S, Haerteis S, Korbmacher C, et al. Neutrophil elastase activates protease-activated receptor-2 (PAR2) and transient receptor potential vanilloid 4 (TRPV4) to cause inflammation and pain. J Biol Chem. (2015) 290:13875-87. doi: 10.1074/jbc.M115.6 42736

74. Hollenberg MD, Mihara K, Polley D, Suen JY, Han A, Fairlie DP, et al. Biased signalling and proteinase-activated receptors (PARs): targeting inflammatory disease. Br J Pharmacol. (2014) 171:1180-94. doi: 10.1111/bph. 12544

75. Xue M, Chan YK, Shen K, Dervish S, March L, Sambrook PN, et al. Proteaseactivated receptor 2 , rather than protease-activated receptor 1 , contributes to the aggressive properties of synovial fibroblasts in rheumatoid arthritis. Arthritis Rheum. (2012) 64:88-98. doi: 10.1002/art.33323

76. Yang YH, Hall P, Little CB, Fosang AJ, Milenkovski G, Santos L, et al. Reduction of arthritis severity in protease-activated receptor-deficient mice. Arthritis Rheum. (2005) 52:1325-32. doi: 10.1002/art.21001

77. Heuberger DM, Schuepbach RA. Protease-activated receptors (PARs): mechanisms of action and potential therapeutic modulators in PAR-driven inflammatory diseases. Thromb J. (2019) 17:4. doi: 10.1186/s12959-019-0194-8

78. Waasdorp M, Florquin S, Duitman J, Spek CA. Pharmacological PAR-1 inhibition reduces blood glucose levels but does not improve kidney function in experimental type 2 diabetic nephropathy. FASEB J. (2019) 33:1096672. doi: 10.1096/fj.201900516R

79. Trice JM, Pinals RS. Dimethyl sulfoxide: a review of its use in the rheumatic disorders. Semin Arthritis Rheum. (1985) 15:45-60. doi: 10.1016/0049-0172(85)90009-5

80. Poo YS, Nakaya H, Gardner J, Larcher T, Schroder WA, Le TT, et al. CCR2 deficiency promotes exacerbated chronic erosive neutrophil-dominated chikungunya virus arthritis. J Virol. (2014) 88:6862-72. doi: 10.1128/JVI.03364-13

81. Setoh YX, Amarilla AA, Peng NYG, Griffiths RE, Carrera J, Freney ME, et al. Determinants of Zika virus host tropism uncovered by deep mutational scanning. Nat Microbiol. (2019) 4:876-87. doi: 10.1038/s41564-0190399-4

82. Setoh YX, Peng NY, Nakayama E, Amarilla AA, Prow NA, Suhrbier A, et al. Fetal brain infection is not a unique characteristic of Brazilian Zika viruses. Viruses. (2018) 10:E541. doi: 10.3390/v10100541

83. Yockey LJ, Varela L, Rakib T, Khoury-Hanold W, Fink SL, Stutz $\mathrm{B}$, et al. Vaginal exposure to Zika virus during pregnancy leads to fetal brain infection. Cell. (2016) 166:1247-56.e4. doi: 10.1016/j.cell.2016. 08.004

84. Martinez-Gutierrez M, Correa-Londono LA, Castellanos JE, Gallego-Gomez JC, Osorio JE. Lovastatin delays infection and increases survival rates in AG129 mice infected with dengue virus serotype 2. PLoS ONE. (2014) 9:e87412. doi: 10.1371/journal.pone.0087412

85. van den Boogaard FE, van Gisbergen KP, Vernooy JH, Medema JP, Roelofs JJ, van Zoelen MA, et al. Granzyme A impairs host defense during Streptococcus pneumoniae pneumonia. Am J Physiol Lung Cell Mol Physiol. (2016) 311:L507-16. doi: 10.1152/ajplung.001 16.2016

86. Bengsch B, Ohtani T, Herati RS, Bovenschen N, Chang KM, Wherry EJ. Deep immune profiling by mass cytometry links human $\mathrm{T}$ and NK cell differentiation and cytotoxic molecule expression patterns. J Immunol Methods. (2018) 453:3-10. doi: 10.1016/j.jim.2017.03.009

87. Lochhead RB, Ordonez D, Arvikar SL, Aversa JM, Oh LS, Heyworth B, et al. Interferon-gamma production in Lyme arthritis synovial tissue promotes differentiation of fibroblast-like synoviocytes into immune effector cells. Cell Microbiol. (2019) 21:e12992. doi: 10.1111/cmi.12992

88. Martin-Antonio B, Sune G, Perez-Amill L, Castella M, Urbano-Ispizua A. Natural killer cells: angels and devils for immunotherapy. Int J Mol Sci. (2017) 18:E1868. doi: 10.3390/ijms18091868

89. Yamin R, Berhani O, Peleg H, Aamar S, Stein N, Gamliel M, et al. High percentages and activity of synovial fluid NK cells present in patients with advanced stage active Rheumatoid Arthritis. Sci Rep. (2019) 9:1351. doi: 10.1038/s41598-018-37448-z

90. Arias MA, Jimenez de Bagues MP, Aguilo N, Menao S, Hervas-Stubbs S, de Martino A, et al. Elucidating sources and roles of granzymes A and B during bacterial infection and sepsis. Cell Rep. (2014) 8:420-9. doi: 10.1016/j.celrep.2014. 06.012

91. Rolle A, Schepers K, Cassadou S, Curlier E, Madeux B, Hermann-Storck $\mathrm{C}$, et al. Severe sepsis and septic shock associated with chikungunya virus infection, Guadeloupe, 2014. Emerg Infect Dis. (2016) 22:8914. doi: 10.3201/eid2205.151449

92. Spaeny-Dekking EH, Hanna WL, Wolbink AM, Wever PC, Kummer JA, Swaak AJ, et al. Extracellular granzymes A and B in humans: detection of native species during CTL responses in vitro and in vivo. J Immunol. (1998) 160:3610-6.

93. Puente XS, Sanchez LM, Overall CM, Lopez-Otin C. Human and mouse proteases: a comparative genomic approach. Nat Rev Genet. (2003) 4:54458. doi: 10.1038/nrg1111

94. Plasman K, Demol H, Bird PI, Gevaert K, Van Damme P. Substrate specificities of the granzyme tryptases A and K. J Proteome Res. (2014) 13:6067-77. doi: 10.1021/pr500968d

95. Sharma M, Merkulova Y, Raithatha S, Parkinson LG, Shen Y, Cooper D, et al. Extracellular granzyme $\mathrm{K}$ mediates endothelial activation through the cleavage of protease-activated receptor-1. FEBS J. (2016) 283:173447. doi: 10.1111/febs.13699

96. Kelso EB, Lockhart JC, Hembrough T, Dunning L, Plevin $\mathrm{R}$, Hollenberg $\mathrm{MD}$, et al. Therapeutic promise of proteinaseactivated receptor-2 antagonism in joint inflammation. $J$ Pharmacol Exp Ther. (2006) 316:1017-24. doi: 10.1124/jpet.105.0 93807

97. Ferrell WR, Lockhart JC, Kelso EB, Dunning L, Plevin R, Meek SE, et al. Essential role for proteinase-activated receptor-2 in arthritis. J Clin Invest. (2003) 111:35-41. doi: 10.1172/JCI16913

98. Lohman RJ, Cotterell AJ, Barry GD, Liu L, Suen JY, Vesey $\mathrm{DA}$, et al. An antagonist of human protease activated receptor2 attenuates PAR2 signaling, macrophage activation, mast cell degranulation, and collagen-induced arthritis in rats. FASEB J. (2012) 26:2877-87. doi: 10.1096/fj.11-201004

99. Jose RJ, Williams AE, Mercer PF, Sulikowski MG, Brown JS, Chambers RC. Regulation of neutrophilic inflammation by proteinase-activated receptor 1 during bacterial pulmonary infection. J Immunol. (2015) 194:6024-34. doi: 10.4049/jimmunol.15 00124

100. Muley MM, Reid AR, Botz B, Bolcskei K, Helyes Z, McDougall JJ. Neutrophil elastase induces inflammation and pain in mouse knee joints via activation of proteinase-activated receptor-2. Br J Pharmacol. (2016) 173:766-77. doi: 10.1111/bph.13237

101. Prow NA, Hirata TDC, Tang B, Larcher T, Mukhopadhyay P, Lubiana Alves T, et al. Exacerbation of chikungunya virus rheumatic immunopathology by a high fiber diet and butyrate. Front Immunol. (2019) 10:2736. doi: 10.3389/fimmu.2019.02736

102. Cook LE, Locke MC, Young AR, Monte K, Hedberg ML, Shimak RM, et al. Distinct roles of interferon alpha and beta in controlling chikungunya virus replication and modulating neutrophil-mediated inflammation. J Virol. (2019) 94:e00841-19. doi: 10.1128/JVI.00841-19

103. Zhao P, Metcalf M, Bunnett NW. Biased signaling of protease-activated receptors. Front endocrinol. (2014) 5:67. doi: 10.3389/fendo.2014. 00067

104. Mihara K, Ramachandran R, Renaux B, Saifeddine M, Hollenberg MD. Neutrophil elastase and proteinase-3 trigger $\mathrm{G}$ protein-biased signaling through proteinase-activated receptor-1 (PAR1). J Biol Chem. (2013) 288:32979-90. doi: 10.1074/jbc.M113.483123

105. Kaiserman D, Bird CH, Sun J, Matthews A, Ung K, Whisstock JC, et al. The major human and mouse granzymes are structurally and functionally divergent. J Cell Biol. (2006) 175:619-30. doi: 10.1083/jcb.200606073

106. Shields CA, McCalmon M, Ibrahim T, White DL, Williams JM, LaMarca B, et al. Placental ischemia-stimulated T-helper 17 cells induce preeclampsiaassociated cytolytic natural killer cells during pregnancy. Am J Physiol Regul Integr Comp Physiol. (2018) 315:R336-R43. doi: 10.1152/ajpregu.0006 1.2018

107. Engin A, Aydin H, Cinar Z, Buyuktuna SA, Bakir M. Apoptosis and its relation with clinical course in patients with Crimean-Congo 
hemorrhagic fever. J Med Virol. (2019) 91:1385-93. doi: 10.1002/jmv. 25467

108. Juno JA, van Bockel D, Kent SJ, Kelleher AD, Zaunders JJ, Munier CM. Cytotoxic CD4 T cells-friend or foe during viral infection? Front Immunol. (2017) 8:19. doi: 10.3389/fimmu.2017.00019

109. Brilot F, Strowig T, Munz C. NK cells interactions with dendritic cells shape innate and adaptive immunity. Front Biosci. (2008) 13:644354. doi: $10.2741 / 3165$

110. Gryka RJ, Buckley LF, Anderson SM. Vorapaxar: the current role and future directions of a novel protease-activated receptor antagonist for risk reduction in atherosclerotic disease. Drugs $R$ D. (2017) 17:6572. doi: $10.1007 / \mathrm{s} 40268-016-0158-4$
Conflict of Interest: The authors declare that the research was conducted in the absence of any commercial or financial relationships that could be construed as a potential conflict of interest.

Copyright $\odot 2020$ Schanoski, Le, Kaiserman, Rowe, Prow, Barboza, Santos, Zanotto, Magalhães, Aurelio, Muller, Young, Zhao, Bird and Suhrbier. This is an open-access article distributed under the terms of the Creative Commons Attribution License (CC $B Y)$. The use, distribution or reproduction in other forums is permitted, provided the original author(s) and the copyright owner(s) are credited and that the original publication in this journal is cited, in accordance with accepted academic practice. No use, distribution or reproduction is permitted which does not comply with these terms. 